\title{
Realism from the 'lands of Kaleva': an interview with Uskali Mäki
}

USKALI MÄKI (Helsinki, 1951) is a philosopher of science and a social scientist, and one of the forerunners of the strong wave of research on the philosophy and methodology of economics that has been expanding during the last three decades. His research interests and academic contributions cover many topics in the philosophy of economics, such as realism and realisticness, idealisation, scientific modelling, causation, explanation, rhetoric, the sociology and economics of economics, and the foundations of new institutional and Austrian economics. He is a coeditor of The handbook of economic methodology (1998); Economics and methodology: crossing boundaries (1998); Rationality, institutions and economic methodology (1993). And the editor of two compilations of essays that have become highly influential to the shaping of the field: The economic world view: studies in the ontology of economics (2001), and Fact and fiction in economics: realism, models, and social construction (2002).

Currently, Uskali Mäki is academy professor at the Academy of Finland. He is also director of the project Trends and Tensions of Intellectual Integration (TINT), based at the department of social and moral philosophy, University of Helsinki. Before settling in Helsinki, he was professor of philosophy of science at Erasmus University Rotterdam from 1995 to 2006, where he was academic director of the Erasmus Institute for Philosophy and Economics (EIPE) since its foundation in 1997. He was co-editor of the Journal of Economic Methodology from 1996 to 2005; founding member, executive board member, and from 2007 to 2008, Chair of the International Network for Economic Method (INEM); and has been a research area coordinator for the European Association of Evolutionary Political Economy since 1992.

EJPE is pleased to present this interview with Professor Mäki, in which he offers some reflections on the aims, current situation, and prospects of the field, as well as on the development of his own thought about the philosophy and methodology of economics.

EJPE'S NoTE: This interview was conducted by Luis Mireles-Flores, PhD candidate at the Erasmus Institute for Philosophy and Economics (EIPE), Erasmus University Rotterdam, and co-editor of the Erasmus Journal for Philosophy and Economics. 


\section{EJPE: Professor Mäki, you have had formal training in both areas:} philosophy and economics. When and why did you decide to specialize in philosophy of economics?

USKALI MÄKI: How nice to be asked about those early years. That sweet nostalgia! It all happened in the early 1970s, at a time when our fieldas an institutionalized research field-did not yet exist. So I was crazy enough to devote myself to a field that would come into existence only many years later. I never thought of it as a risky investment, but in a sense that is what it was, and indeed it turned out to be one that was to yield lovely returns later on. I don't think I actually anticipated the eventual emergence of our research field, but I did have a very strong opinion that it should. This normative obsession put me on that track.

The intellectual commitment and normative obsession derived from my early experience as an economics student. Having previously studied statistics, math, sociology, and philosophy, I started studying economics during my second undergraduate year. I recall I made the choice since I wanted a subject that would be both intellectually rigorous and socially relevant. But the early experience was somewhat shocking.

Based on everyday experience, I knew that I am not an expected utility maximizer, and I knew that the economy out there was far from perfectly competitive, and I thought I knew many other facts about society and human behaviour that those models that were taught to us appeared to distort so shamelessly. So I wondered what to make of economics, whether this is good science after all, and how on earth I could judge whether it is.

Another feature of the situation in the early 1970s that prompted similar questions was the popular claim that economics is in a crisis, and the related proliferation of rival schools such as versions of Keynesian and Monetarist, Austrian and Marxian, Institutionalist and early Behaviouralist approaches (no wonder Kuhn's notion of scientific crisis was frequently cited at that time). I wondered how to rationally judge the relative merits of these approaches. Where should my intellectual sympathies go, and how could I possibly justify my choice, whatever it might be?

So there was a challenge that could not be escaped. And it was a philosophical challenge, a challenge that could only be treated by exploiting philosophical concepts and theories about science. The step I took was to combine my studies in economics with my studies in philosophy: to look at economics from the point of view of the 
philosophy of science. Otherwise I could not possibly have survived my further studies in economics. Indeed, I did survive them, and this combination of the two disciplines itself not only survived, but was destined to flourish collectively in the later years.

I would like to mention that the world then was very different from the one that the present generation of aspiring philosophers of economics lives in. The literature was far more limited than today, there were no educational programmes or even competent individual guidance (I envy those of you with this privilege at EIPE and elsewhere today!), no collectively held research agenda was in place, authority structures characteristic of a research field were missing. The future was open, and the adventure could begin. It would become a wonderful adventure.

Were there any particular readings or authors that you recall as having an important influence on your interest in philosophy of economics?

Oh boy, those were years when I must have used most of my time for reading! Richard Lipsey's An introduction to positive economics was the textbook used in the introductory course I had taken. This book had an unusually long opening chapter that dealt with methodological issues, and the whole book was designed so as to bring theory and empirical evidence in some contact with one another. Lipsey had been a member of the M2T (for 'methodology, measurement, and testing') group that was influenced by Popper's ideas. Lipsey's introduction led me to read Friedman's 1953 essay on 'The methodology of positive economics' that I considered, on my first reading, a scandal, indeed an intellectually irresponsible apology for dubious economic theories. (As you know, my perception of Friedman's F53 has gone through major changes since that early exposure.)

I then started reading everything that I got hold of. I dug into the history of methodological and philosophical statements about economics and read all the classics and examined the debates that there had been, from Senior and Mill, Marx and Menger, Cairnes and Marshall, through Mises and Robbins, Hutchison and Hayek to Machlup and Samuelson, including the German and British Methodenstreiten, Keynes versus Tinbergen, the measurement without theory debate, and of course the F53 debates in the 1950s and 1960s. 
I also read virtually everything that had been written in the course of the history of Finnish economics on methodological and philosophical issues. Later, I published a lengthy essay outlining the history of methodological thinking in Finnish economics around issues such as history versus theory, role of math, nature of models, and role of values in economics. The currents I was able to identify were similar to those in many other countries.

There was little new published during those early years in the 1970s, so it was easy to read everything that was. They included some of Larry Boland's articles as well as Spiro Latsis's papers and his edited 1976 volume on Method and appraisal. There was a peculiar book entitled Rational economic man (1975) by Hollis and Nell that I studied with great care. Later, much more was to appear by people like Alex Rosenberg, Dan Hausman, Mark Blaug, Neil De Marchi, Bruce Caldwell, Wade Hands, and an increasing number of others. But that then meant there was a research field in the making.

Naturally, readings in the philosophy of science were very important. On this I was not on my own, but rather received top rate guidance from professors in Helsinki: Raimo Tuomela, Ilkka Niiniluoto, and others. I studied basic texts such as Nagel's The structure of science (1961) and Carl Hempel's Aspects of scientific explanation (1965) plus many other authors popular at that time, such as Stegmüller, Popper, Lakatos, Feyerabend, and Laudan. My particular philosophical outlook, scientific realism, was influenced by authors such as Sellars, Cornman, Hooker, Smart, Boyd, Bunge, and Putnam. Among other very important readings were Ilyenkov on the abstract and the concrete, Nowak on idealizations, and Vaihinger on the Als-Ob (in 1979 I taught a course on idealizations and fictions in economics). I also read quite a lot of Rom Harré's works and found them inspiring. And I must confess I was influenced by Roy Bhaskar's first two books (1975 and 1979). I even used some of their vocabulary when I started teaching undergraduate courses in the philosophy of the social sciences in the last years of the 1970s. But as I tried to apply Bhaskar's ideas in my emerging realist philosophy of economics, within a few years I abandoned them as too simplistic for the purpose (as you know, some years later Bhaskar's ideas were discovered by Tony Lawson and used in arguments that I think distort facts about economics).

This early disappointment with Bhaskar helped me realize there was nothing available in the philosophical literature that would be directly 
applicable to such a complex and peculiar subject as economics (partly for these reasons, I also never got very excited about the project of applying Popper and Lakatos to economics). I had to start creating my own framework. This is in no way surprising. An up-to-date philosophy of economics did not exist. It had to be created.

\section{From your personal perspective, what are the principal aims of a discipline like philosophy of economics?}

There are many goals. Descriptive analysis of theories, methods and practices; diagnosis and explanation of epistemic performance; normative assessment and institutional design; and of course, not a fully separate task, the clarification of tricky concepts and implicit presuppositions. Economics is a very complex subject matter, and any given account of it will only highlight some of its limited aspects, serving only limited purposes. Overgeneralized and oversimplified accounts abound, and they are just that: overgeneralized and oversimplified. One cannot do all at once, both accounting and appraising, and perhaps suggesting revising the core features of economics in terms of one simplistic formula-even though these sorts of endeavour appear to have a lot of rhetorical appeal.

On the other hand, given that economics is such an immensely powerful epistemic institution in contemporary society, philosophy of economics should not remain an insulated puzzle-solving activity exercised in tall academic ivory towers. It should take on societal responsibilities in the collective and interdisciplinary monitoring of the epistemic and political performance of economics. Economics is all too important to be left to economists alone.

I recall the time when we had just created EIPE in Rotterdam in 1997. I envisioned a possible vocation for our future graduates in the philosophy of economics, one that would give the field a high profile as socially responsible and influential activity. The idea was simple, and I still think the world should welcome it. Given that economic theories and research results play such a powerful role in shaping policies and worldviews all over the place, and given that decision makers (with or without an education in economics) must rely on the expertise of professional economists, decision makers should consult experts on economics on top of experts in economics in order to be in a better position to judge the quality of information and advice provided by economists. This quality has to do with things such as reliability and 
various hidden background presuppositions. So there should be demand for expertise on economics, and this demand should be met by producing a supply of such expertise by way of educating specialists in the philosophy and methodology of economics. I optimistically envisaged EIPE would do just that.

Well, that vision has still some way to go to be fully implemented, but let me mention a small example that gives a hint as to what such a dream world could be like. In 2002, the Central Bank of Austria in Vienna organized a one-day workshop on 'truth in economics', and invited me to play a major role in it. I understood Austrian economists had been challenged with some sort of epistemic legitimacy issues, and they felt like needing some philosophical guidelines for making their case. The deliberations of the workshop were recorded and later broadcast on the Austrian radio. I found it a fascinating experience. Central Bank economists interested in issues of truth!

One gets an entirely different idea of the goals of the philosophy of economics when looking at it from the point of view of the philosophy of science. I can see two kinds of services. First, philosophy of economics is just one of the many philosophies of $X$ (where $X$ can denote physics, chemistry, biology, cognitive science, archaeology, etc.). At the highest level of abstraction, general philosophy of science produces accounts of science in general. Philosophies of economics, geology, psychology, and the like, produce accounts of their target disciplines at lower levels of generality. But naturally there is interaction between these levels of generality in both directions. Thus philosophy of economics produces accounts of its target discipline that may be used for purposes such as testing and developing more general accounts of science. In other words, philosophy of economics may have the goal of providing evidential and productive services to the rest of philosophy of science. A philosopher of science examining economics is welcome to inform other philosophers of science (who examine science in general or some other special discipline such as biology) about his or her discoveries concerning economics.

The second sort of service amounts to contributing to the "naturalization" (or rather "socialization" or generally "scientifization") of the philosophy of science. Consider science as one institutionalized form of the use of the human brain. In order to understand science, one has to understand its institutions as well as the human brain. Together with cognitive and other sciences, economics can be used as a scientific 
resource for this purpose. The supposition is that science has an economic aspect; it can be viewed as an economy. Now if economics is utilized in such a project as a resource, then it becomes necessary to analyze and assess that resource for its credibility and reliability. This is where philosophy of economics becomes indispensable.

You asked about my personal perspective. Let me take this to allow for tracing a development in my own orientation in producing and publishing my research. Even though I was trained in philosophy (like Alex Rosenberg and Dan Hausman), I was first employed by an economics department and regularly taught 'economic methodology' to economics students for more than a decade, from the late 1970s to the early 1990s. During that period, most of the other activists (like Neil De Marchi, Mark Blaug, Larry Boland, Bruce Caldwell, and Wade Hands) had a background in economics and worked for economics departments, and also were closely connected to the rising wave in the study of the history of economics.

Recall this was also the period when there was a lot of talk about the "crisis" of economics that I mentioned earlier. All this shaped much of the agenda of the field. It became largely a project of historically spirited normative appraisal, with some participants having the hope of somehow helping make economics better as an empirically controlled science. But the appraisal was based on rather limited concepts and questions, shaped by Popperian and Lakatosian frameworks. I never shared these frameworks, but I did address pretty much the same audiences as these fellow workers: namely other economic methodologists, historians of economics, practicing economists-rather than philosophers of science. Yet I think I largely acted like a philosopher, annoyed by conceptual confusions and obsessed with conceptual clarification. This must have had an impact on my style of writing, too. But I now feel I may have been too optimistic about making an impact. I fear some of my nuanced analyses may have been too much even for my fellow economic methodologists.

I have only later engaged myself more closely in the debates in the general philosophy of science. I have made the pleasant (and also in some other ways unpleasant) discovery that many of the ideas I developed while addressing non-philosophical audiences are now fresh and topical stuff for philosophers. This means I need to make another effort in presenting and reframing those ideas to a new audience (while, happily, getting a chance to refine them further). There are gaps 
between intra-field conversations that need to be bridged. Intra-field inquiries have not proceeded in step with one another, so there is a challenge for inter-field coordination. This task is helped by the fact that philosophy of economics has gradually established itself as a serious partner in the philosophy of science.

Let me mention an example of this last observation. Elsevier is presently busy with a giant publication project: a series of 16 volumes of handbooks in the philosophy of science. Next to volumes devoted to the philosophy of mathematics, physics, chemistry, biology, and so on, there will be one volume on the philosophy of the social sciences and another volume on the philosophy of economics. Not bad at all?

In 1992, you wrote that the method of isolation was ubiquitous in economics. What are your ideas today about the method of isolation in economic science? Has there been any significant change or expansion on your ideas about this topic?

This was indeed an important insight. Among other things, it helped me see the point of many of those disturbingly unrealistic assumptions that so badly annoyed me when I started my economics studies. The idea emerged gradually through my readings of Marshall, von Thünen, and Nowak and the rest of the Poznan school in the course of the 1980s. (Let me say here that it is a shame that many Anglo-American philosophers of science tend to ignore the fact that the philosophers of the Poznan school were the pioneers of the study of idealization in science. This is another example of harmful and unfair metropolitan provincialism, as I would call it.)

One important idea was to connect idealization and isolation. Idealizations are performed by false assumptions that suggest that a variable takes on values such as zero or infinity or other distorting value (zero transaction costs, instant adjustment, complete and transitive preferences, ceteris paribus). Such assumptions have a function, and one cannot judge those assumptions without understanding their function. I argued their function is often to help effect an isolation. This is what I've called the experimental moment in theoretical modelling. The key notion is that of controlling for other things in order to isolate one thing. The economist neutralizes those other things in order to let the isolated thing act on its own, as it were. In laboratory experiments, this takes place through causal manipulation, while in theoretical modelling it is accomplished by way of assumption. They both isolate. 
I recall it was a relief to reach this insight. It would transform the terms of debate, I believed. From now on we could ignore simple criticisms of falsehood in assumptions. We should not focus just on individual assumptions and their realisticness without a good grasp of the function they serve in a larger context. This would also change the terms of philosophical labelling: just accepting and using false assumptions would not make anyone an instrumentalist. Falsehood is a tool for a realist, too. Among other things, in the exegesis of Friedman's 1953 essay, this helped me turn against the mainstream reading of him as an instrumentalist. I have argued for reading the essay as a realist statement instead.

There is a special challenge that a realist account of idealization and isolation must meet. This is the fact that I mentioned in my 1992 paper: many idealizing assumptions are motivated by mathematical rather than metaphysical reasons. They enhance the tractability of modelling and facilitate mathematical derivations. This is a concern that has been discussed by people like Frank Hindriks, Nancy Cartwright, and Anna Alexandrova. As I see it, the challenge is to develop criteria for assessing such tractability assumptions from a realist point of view so as to tell those that distort facts that shouldn't be distorted from those that don't.

Change or expansion? Oh yes, the framework keeps evolving. And it appears to apply widely. In my recent interventions into the debates over models and modelling, I have employed the idea of isolation in my MISS account of models (models as isolations and surrogate systems). In my work on explanatory progress, I have expanded the framework by incorporating the idea of isolations and de-isolations (as well as reisolations) among both potential explananda and potential explanantia of a model or theory. These operations take place as responses to challenges in a "dynamics of debate" that drive explanatory progress. The roles of causal mechanism and explanatory unification can also be highlighted in the isolation framework. In 1992, I drew a distinction between intra- and inter-disciplinary isolation, but have only recently started applying it as part of the present project on interdisciplinarity. I am presently working on incorporating ideas about contrastivity and difference-making in the overall framework of theoretical isolation. I think this will further extend its applicability and fruitfulness. 
Some of your initial work in the field has been focused on the analysis of two topics: Austrian economics and the Rhetoric of economics. Can you elaborate on how these subjects have played a part in the development of your thinking? Perhaps you can also briefly sketch your current opinions on both themes.

Indeed, that's right. The two stories are somewhat different. At least three reasons lie behind my early interest in Austrian economics. It was one of those traditions that experienced a mass scale revival in the 1970s. It offered what seemed to be the strongest case for free market thinking. Perhaps most importantly, maybe next to Marxian economics, it has been the most philosophically self-reflective tradition in economics. Thanks to this last feature, there was a lot to read and analyze in the philosophical and methodological writings of Menger, Mises, Hayek, Lachmann, as well as in the secondary philosophical literature. I also read what these and other authors, most importantly Israel Kirzner, wrote in their economic work.

The papers I then published on Austrian economics dealt with its methodology and metaphysics. They were intended to serve two purposes: to provide novel interpretations of some Austrian ideas and to develop ideas for more general use. For this latter purpose, Austrian economics served as a source of inspiration and as a test ground for philosophical inquiry. I offered a new reading of Menger's idea of economics as an exact science in terms of recent philosophical work on laws as second-order universals (by David Armstrong and others). I analyzed notions such as money (as a collection of causal powers), the market process (as a causal process; here I modified Wesley Salmon's account of causal process), entrepreneurship (as a causal power), the relationship between realism and subjectivism (as a combination of ontic subjectivism and ontological objectivism), and the invisible-hand mechanism and invisible-hand explanation (as essentialist and howpossibly explanation). There was also a contribution to the literature on hermeneutics and Austrian economics that made an interesting start in the late 1980s but seems to have discontinued (which is a big pity, in my view). I believe all these ideas are still relevant to contemporary concerns not only in regard to Austrian economics, but more widely. I should perhaps now emphasize their possible broader relevance given that few Austrian economists seem to have paid much attention to these papers. Partly due to the unresponsiveness of Austrian economists to my work, I haven't done anything in this area for many years (yet one 
day I hope to pull together these contributions in the form of a book). My current work looks more into areas such as new institutional economics, behavioural economics, and geographical economics.

The story behind my interest in the rhetoric of economics is different. In the beginning of the 1980s, Ronald Coase and Willie Henderson published papers on rhetoric and metaphor in economics, then in 1983 there appeared D. McCloskey's famous piece in the Journal of Economic Literature, and Arjo Klamer's Conversations with economists. McCloskey and Klamer launched a campaign in support of the rhetorical perspective, combining it with some very radical philosophical claims. What happened was that they proposed joining the recognition of rhetoric in economics with antirealist philosophy in one package, as if they belonged together: if you choose rhetoric, you also must choose antirealism. Many readers were misled to consider the recognition of rhetoric as part of such a package. Some bought the package, some others didn't. Some bought antirealism because they believed they had to, otherwise they wouldn't get the valuable idea of rhetoric. Some others did not buy rhetoric because they believed they would then have to buy antirealism as well, and this turned them away.

What I saw was conceptual confusion and ungrounded antirealism, and this triggered my pedantic obsessions and realist instincts. I set out to demolish the package. One result was an ongoing debate with McCloskey and Klamer; it has now lasted more than twenty years. Another result was an account of rhetorical realism, or realist rhetoric.

So I have tried to show that rhetoric and antirealism do not necessarily belong together, and that a much better option would be to combine rhetoric with realism. Rhetoric is real and powerful in scientific practice, so it must be recognized and examined. But rhetoric is neutral with respect to the realism versus antirealism issue. So one is free to link rhetoric with realism.

This project, and the controversy with McCloskey, has been a lot of fun and also very useful. I have been forced to develop an account of rhetorical realism as an alternative to rhetorical antirealism. Another nice thing is that the study of the rhetoric of economics has highlighted one way in which economics is a socially shaped activity. It is unfortunate that the rhetoric of economics project does not seem to have made progress for many years now. There is much more to be done here by serious students of the rhetoric of scientific inquiry. 
Not long ago, in 2005, you published an article explaining and arguing for what you have labelled 'local scientific realism'. Can you elaborate on how this conception differs from traditional realist positions towards science?

This idea is related to the differences of levels of generality in philosophical accounts of science that I mentioned earlier. The arguments for local scientific realism provide an instructive case against the popular practice of borrowing ideas from general philosophical literature and applying them directly to economics or any other specific discipline.

The dominant conceptions of scientific realism in the philosophy of science are supposed to offer general accounts of science. But I think they largely fail as such accounts. And I think they do not fail because some disciplines are not real sciences or because some disciplines had better be interpreted in antirealist terms. I think they fail because they are too thick and specific. And I think they are too thick because they are designed so as to fit with some of the most successful parts of physics. So in fact they are local realisms, but they are typically presented as global or general views of realism about science.

Among the typical ingredients in these supposedly general conceptions one can find the ideas that scientific theories postulate unobservables (the electron serving as the paradigm example); that those entities exist mind-independently; that current theories about them are mostly at least approximately true about them; that thanks to these achievements, scientific theories are predictively and technologically successful.

These conceptions of what scientific realism entails about science have then prompted criticisms and debates such as those related to the 'no-miracle' argument and pessimistic induction. They all take place within the framework of those principles without questioning them.

In my view, this is fine and nice, but only within limits. Beyond those limits, the consequences are unpleasant for those scientific disciplines and research fields that do not conform to such principles. Either they do not qualify as science at all or they are expelled into the arms of antirealist philosophies of science. Like many other disciplines, economics would immediately go to one of these dustbins.

The way to avoid such consequences is to do two things. First, if we want to have a global or general scientific realism, it must be made very thin and abstract. I have called such a global version minimal scientific 
realism. I have suggested its principles include that the objects of scientific theories may exist (rather than exist); that they exist (if they do) science-independently (rather than mind-independently); that current scientific theories are possibly true (rather than true). And nothing is required about unobservability or technological success.

The second thing is to go local when considering any particular scientific discipline in realist terms. Those global minimal principles are then specified and amended depending on what is the case at any particular local level. This means we are likely to have a number of local scientific realisms tailored for specific disciplines and fields, and perhaps theories: scientific realism about chemistry, about geology, about quantum mechanics, about evolutionary biology, about microeconomics, and so forth. Naturally, local and global realisms should be in harmony with one another. Minimal global realism should be implied by all local realisms.

I hope this vision will help to modify the terms of the realismantirealism debate and also to rehabilitate the importance of local philosophies of science, such as the philosophy of economics.

\section{And what would a local realist approach to economics look like then?}

Well, this is exactly the big ongoing project, so no final formulations can be given yet. But surely many ideas can be outlined at this point. That economics is largely a non-experimental social science has major ramifications for any idea of realism about it.

Economic theories do not seem to postulate unobservable entities akin to electrons. Economics is about commonsensibles as I've called the various objects that are familiar from everyday experience: firms and households, preferences and expectations, money and prices, wages and taxes, etc. These things do not exist mind-independently, but they do have a fair chance of existing science-independently provided we take this in a constitutive rather than in a causal sense. The causal sense of science-dependence can be permitted to take care of situations in which ideas produced by academic economics are adopted by social actors with consequences for their behaviour, as in the so-called self-fulfilling and self-defeating prophesies.

Scientific realism about economics is an apt position also because the explananda of economic theories are so often products of various invisible-hand mechanisms. The causation of what happens is often not transparent; therefore scientific models of these non-apparent invisible- 
hand mechanisms are needed. And what science identifies as causally responsible exists independently of that science in the sense of not being conceptually constituted by it.

However, predictive and technological success cannot be required of economics in order for it to be compatible with scientific realism. And given the massive epistemic uncertainty when dealing with an immensely complex and effectively uncontrollable subject matter like society, we cannot require that economic theories and models be established as true as a condition for realism to apply. What we can include in a realism about economics is a normative dictum that truths about the real world should be pursued.

As a special realist principle of epistemic justification let me mention the idea of ontological unification. The capacity of a theory to unify a variety of different kinds of phenomena can be taken as speaking in favour of the theory's truth. The intuition is that it would be strange if a false theory had this capacity. But the realist should add that not just any sort of unification will do. A theory that can be used only for logically deriving descriptions of various classes of phenomena may also be false. So one should require that the theory unifies the phenomena ontologically by showing that they are of the same kind after all: they are made of the same stuff or are produced by the same causes, and so on. Now this is very relevant to the analysis of economics given that economics is obsessed with taking unification as far as possible, also beyond its traditional disciplinary boundaries by aspiring to explain not only phenomena of money and trade but also those of marriage and crime in terms of rational choice in a market. For a realist to regard this favourably, ontological unification is required.

In addition to your endorsement of scientific realism, and perhaps as a consequence of it, your work is also full of references to the notion of truth. What is the role of truth in your philosophy of economics? And, furthermore, is economics a science that aims at truth?

You are right, I've been rather unashamed in talking about truth. As you know, we are living the age of "bullshit" (as Harry Frankfurt puts it), characterized by an irresponsible lack of interest in truth and what is true. I don't share this cultural inclination at all, but rather follow my own strong and perhaps naïve intuitions. If a representation suggests that $F$ is the case and if as a matter of fact $F$ is the case, then the 
representation is true. That's about the simplest way of putting the intuition.

Economists-and it seems most philosophers of economics-have an uneasy relationship with the notion of truth. At least they largely try to avoid using terms such as 'true' and 'truth'. At the same time, there seems to be no similar difficulty with 'false' and 'falsity'. Numerous surrogate terms are actively used, such as 'right', 'correct', 'valid', and so on. But I don't think I've ever seen the meanings of such "escape terms" explained. So using them offers no improvement compared to using the terminology of veracity.

Then there are those who are happy to use the terminology of truth, but do not intend it to be taken literally. When they talk about 'truth', they turn out to mean something different. They reduce truth to something else, such as predictive success, persuasiveness, coherence, or socially constructed agreement. Such views of truth enjoy some popularity, and I have resisted them by trying to reveal their counterintuitive implications. For example, long ago there was a socially constructed agreement that the earth lies at the centre of the universe, yet this collectively held belief was false; not because people have changed their minds, but because of the structure of the universe. On my rhetorical realism, one does not produce the world and truths about it by persuading audiences. Truth is not a matter of persuasiveness as on the antirealist view of rhetoric, but persuasion in appropriate institutional conditions may promote the discovery, communication, and acceptance of truths about the world.

I can be pretty precise about the role that the notion of truth has played in my arguments about economics. There is the normative role: economics should pursue truths about the economy. The descriptive role is more nuanced. I don't claim economists pursue truths (while I believe some do, some others don't). I don't claim that (most, many, or any) economic models and explanations are true. Many of my arguments are even-if arguments: Even if so-and-so, this model or explanation may be true. Even if its assumptions are false, a model may be true. Even if the model radically simplifies an immensely complex real-world phenomenon, it may be true. Even if a model predicts poorly, it may be true. Even if only few economists (or none at all!) are persuaded to accept a model, it may be true. This I take to be sufficient for a realism about truth in economics. 
So I have put forth possibility arguments. These arguments do not imply that any given theory or model is actually true. They just suggest that a theory or model may be true even though it has some further properties that might appear to speak against its truth. Now, it would be nice to get from such possibility judgements to claims about actually achieved truth. I have tried to take steps towards this direction by outlining some further constraints the meeting of which makes a difference for the likelihood of actual truth acquisition. These include the idea that persuasion among economists had better take place in dominance-free institutional conditions and the idea that economic theories and models had better be in line with our general views about the way the world works (this is what I've called the ontological www constraint). But I think there are limits beyond which one cannot get in one's capacity as a philosopher of economics. It is ultimately up to (perhaps philosophically informed) practicing economists to judge whether any given theory or model actually is or is not true.

Of course, the difficult issue remains: what is it for a model to be true? Philosophers of science have neglected this issue or have adopted the straightforward position that models are the sorts of entities that cannot be true. In a forthcoming article, I argue that perhaps they can, and I support this with some novel arguments that re-examine both notions, those of 'model' and 'truth'. I am very curious to see how this initiative will be received.

Indeed, some of your most recent work has been on the role of theoretical models in economic science. Can you give a more detailed account of your position on this topic and of how it connects to your previous research?

I must say I am very excited about this theme. Given that economics is very much a modelling discipline, this helps me understand many characteristics of the subject. Models and modelling are also among the most popular topics in the philosophy of science today. In the philosophy of economics, valuable contributions have been produced by Mary Morgan, Robert Sugden, Marcel Boumans, Nancy Cartwright, Tarja Knuuttila, Julian Reiss, and others. I am developing an account of theoretical models that is slightly different from the others that have been proposed.

In my account, models are imagined small worlds that can be described variously, such as verbally, visually and mathematically. These 
imagined toy worlds serve as surrogate systems that can be used as representatives of some real world systems (or some other target systems, such as theories). The epistemic point of such surrogate systems is the wish that by directly examining their properties and behaviour ("let's see what happens in this model"), the modeller will indirectly learn about the target system. For this to be possible, the model must resemble the target system in certain important respects. In order for the model to qualify as a representation of a target, I do not require that it actually does resemble, but only that issues of resemblance can be reasonably raised. Moreover, in order for a model to resemble its target, it is sufficient that there be just very limited similarities between the two; no detailed and comprehensive correspondence is needed. The desired and required respects of resemblance in any particular context are determined by ontological constraints (the properties of the target) and pragmatic constraints (the purposes and audiences of modelling). All these various elements of models as representations are identified and coordinated by what I call a 'model commentary'.

Isolation is in the picture as a major part of this MISS account. Models as imagined toy worlds have the function of isolating limited aspects of their targets. Models do not characterize their targets in all their rich detail, but rather pick out features that are viewed as relevant for some purpose of model use. Idealizing assumptions are elements in model descriptions that serve as vehicles for making these isolations explicit. Models often isolate causal mechanisms in very skeletal form, and it is hoped that the mechanism in the imagined model world is also in operation in the real target world.

While this account should help to swallow a lot of unrealisticness in models as entirely reasonable and well-taken, it should also help distinguish good and bad modelling exercises from one another. I have suggested a distinction between surrogate models and substitute models for this purpose. Surrogate models can be intended as bridges to their targets thanks to the fact that issues of resemblance are taken seriously, so one hopes to learn about the target by examining the model. Substitute models, on the other hand, literally substitute for their target, and no issues of resemblance arise: examination of the model only informs about the model but provides no information about the properties of any target system. 
As you can see, this is a way of reconceptualising some of the ageold issues in, and about, economics. Naturally, the notions of surrogate model and substitute model, and how one should go about recognizing and distinguishing them in practice, require a lot of further scrutiny.

You are currently heading a seemingly very ambitious research project called Trends and Tensions in Intellectual Integration (TINT), sponsored by the Academy of Finland. Can you please explain what are the main characteristics and goals of this project?

This is indeed an ambitious endeavour. It is motivated by current developments in the social sciences in their interdisciplinary relations. Looking at these developments from the point of view of economics, there are two trends, both involving interesting tensions. Economic ideas are increasingly used in the study of phenomena traditionally examined by other social sciences such as sociology, political science, law, human geography, and science studies. Economics itself, in particular its depiction of human behaviour, is increasingly put under the pressure of progress in experimental psychology and neurobiology. It is various aspects of this complex web of trends and tensions that we examine. The perspective is mainly philosophical. This means that the core concepts include those of model, mechanism, explanation, unification, reduction, emergence, level, domain, progress, and of course, those of discipline and field.

We expect to learn many sorts of thing. One is the variety and mechanisms of interdisciplinary interactions, including how special disciplines may resist engaging in such interactions. The other is the nature of participant disciplines. Interdisciplinary interactions provide a particularly revealing source of information in this respect. So we learn about political science and sociology, psychology and neurobiology, and given that economics is a major focus of attention, we learn new things about economics by looking at how it relates itself to other disciplines.

The undertaking is not only interdisciplinary itself, but also very international. We have been able to recruit some of the best post-docs in the field to our ranks from abroad, such as EIPE graduates Emrah Aydinonat and Caterina Marchionni, as well as Till Grüne-Yanoff who graduated from the LSE. We also have an active visitors programme through which TINT has hosted many PhD students and more advanced players from abroad. The Finnish team members are very competent, creative and productive, including Petri Ylikoski, Aki Lehtinen, Jaakko 
Kuorikoski, Tarja Knuuttila, and others. It is a fantastic team. Regular seminars, workshops and conferences are among our working tools.

And to conclude, could you offer a succinct diagnosis of the present state of philosophy of economics and perhaps some of your expectations about its future development?

Well, that's much to ask, but it is a nice challenge. First of all, through all these years I have witnessed tremendous progress in the field. The field is now far larger than ever. Many more people are active in it. And many of the new activists are well educated for the task. Educational programmes-most notably that of EIPE-are making a difference. Institutes and greater concentrations of experts (e.g., Rotterdam, Helsinki, London, Amsterdam, Madrid, Duke, Alabama, Buenos Aires) are proliferating. New topics and issues have been addressed; many previously dark aspects of economics have been illuminated. Standards of quality are improving. All this makes me very happy.

From a social point of view, five trends strike me as important. A numerous and capable younger generation is entering the field and is making new important initiatives. A growing proportion of the activity now takes place in Europe relative to North America. A growing share of the activity now takes place in philosophy departments relative to economics departments. The division of intellectual labour is growing in the field: practitioners increasingly specialize in limited topic areas. This trend is an indication of the maturity of the field, but it has the unfortunate consequence that sound synoptic overall visions will become harder to create. Finally, partly in reaction to that, there will be more collaboration, both among specialists in the philosophy of economics and between them and others, such as practicing economists.

As to the topics of our inquiries, some presently popular ones will stay and others will emerge. I expect issues related to assumptions, models, and their realisticness to remain at the core of the field. Further inquiries into economic causation will be made. Economic explanation is one of the under-researched topics, and much more will be done on it. Prediction and forecasting are badly neglected, so there is a call for more attention. Traditional issues of testing will stay on the agenda and will be addressed by looking at the nature and roles of a variety of kinds of evidence. I expect the issue of scientific progress to make a comeback onto the agenda, but this time framed in updated philosophical terms. 
The trend has been towards analyses informed by case studies, and I expect this to continue. I also expect this to be balanced by sophisticated conceptual work on some of the meta-theoretical notions that are not sufficiently well understood. There will also be further analyses of some core concepts of economics, such as those of rationality, wellbeing, market, money, firm, and others.

I expect more focus on interdisciplinary relations since they increasingly shape and reshape theoretical and explanatory activity in economics, both in relation to other social sciences and in relation to cognitive and life sciences. The coming years will see more analyses of fields such as behavioural economics, neuroeconomics, institutional economics, evolutionary economics, and geographical economics, but also of the prevailing ambitious trends towards integrating the social sciences with the cognitive and life sciences. The contributions by folks like Don Ross, Jack Vromen, John Davis, Harold Kincaid, Erik Angner, Caterina Marchionni and myself will be followed up by many others.

I expect there to be more attention to interdisciplinary relations also in practical policy contexts, such as those of climate change and health care. Related to this, I expect the philosophy and methodology of applied economics outside of academia to become an honourable area of inquiry. This is also very much needed, given its scale and societal importance (maybe some of our young experts who will not stay at universities, but will find jobs at the various economic research institutes, are able and willing to take on this task as part of their new job description).

I expect methods used or usable by economics to attract more attention. The scrutiny of econometric and experimental methods will continue, building on the work of people like Aris Spanos and Francesco Guala, and this will be supplemented by analyses of simulations and surveys. I expect there to be debate over qualitative methods as in other social sciences. In this connection, hermeneutics will make a comeback. And I expect there to be more work on the philosophy of macroeconomics, not just by Kevin Hoover and Roger Backhouse.

I expect the trend towards a more social image of economics to continue. Not only are we going to see more detailed analyses of the social structure and dynamics of academic (and hopefully nonacademic) economics, but we are going to be more informed about the external social contexts in which economics has evolved and is being 
done. Others will follow Phil Mirowski's footsteps. It is a special challenge to draw philosophical conclusions from these studies.

I expect the trend to continue towards economics itself, together with cognitive science, playing a growing role as a scientific resource in science studies as in Jesus Zamora-Bonilla's work. Economics of economics will be an exciting special case that offers many new opportunities for self-referential investigations. I also expect and hope that philosophers of economics will contribute, in the spirit of social epistemology, to the redesign of academic institutions that are likely to enhance the capabilities of economic inquiry to produce true and (societally and humanly) relevant information about the real world.

May I conclude with some observations about audiences? There has been a chronic complaint (sometimes associated with a sort of self-pity) that practicing economists are not interested in what philosophers and methodologists say about economics. Some think this is an outright failure of our field. The premise behind this is that making a difference for research practices in economics is a major goal of our metascientific activity.

I would look at this issue somewhat differently. I do strongly believe that a close contact with economic research practice is important for epistemological reasons so to speak: to be adequate, philosophical accounts of economics must be well informed about what they are about. I also think that reaching the audience of practicing economists would be nice, and we should work for it, but still I would not think of a failure in this task as manifesting a fatal failure of the field (it is perhaps as much a failure of economics: it takes two to tango after all). There are other important audiences-such as philosophers of science, other social and natural scientists, policy makers, lay public - that have or should have an interest in being enlightened by our philosophical analyses of economics. At least the first two of these are increasingly receptive to what we say. Philosophers of science have welcomed philosophers of economics to their ranks and are eager to learn from us. Other social scientists are puzzled by the increasing intrusion of economic ideas into their disciplines and are also eager to learn from us in deciding what to make of this.

As I said earlier, economics is too important to be left to economists alone. By extension, the fate of the philosophy and methodology of economics should not be left at the mercy of economists alone. 


\section{SOME RECOMMENDED TEXTS WRITTEN OR EDITED BY USKALI MÄKI:}

[Forthcoming] Models and the locus of their truth. Synthese. http://www.helsinki.fi/filosofia/tint/maki/materials/ModelsSyntheseC.pdf

[Forthcoming] MISSing the world: models as isolations and credible surrogate systems. Erkenntnis. http://www.helsinki.fi/filosofia/tint/maki/materials/ModelsErkenntnisE.pdf

2009. The methodology of positive economics: reflections on the Milton Friedman legacy, ed. Uskali Mäki. Cambridge: Cambridge University Press.

2005. Reglobalising realism by going local, or (how) should our formulations of scientific realism be informed about the sciences. Erkenntnis, 63: 231-251.

2005. Economic epistemology: hopes and horrors. Episteme. A Journal of Social Epistemology, 1 (3): 211-220.

2004. Theoretical isolation and explanatory progress: transaction cost economics and the dynamics of dispute. Cambridge Journal of Economics, 28 (3): 319-346.

2004. Realism and the nature of theory: a lesson from J. H. von Thünen for economists and geographers. Environment and Planning A, 36 (10): 1719-1736.

2003. 'The methodology of positive economics' (1953) does not give us the methodology of positive economics. Journal of Economic Methodology, 10 (4): 495505.

2002. Fact and fiction in economics: realism, models, and social construction, ed. Uskali Mäki. Cambridge: Cambridge University Press.

2001. The economic world view: studies in the ontology of economics, ed. Uskali Mäki. Cambridge: Cambridge University Press.

2001. Explanatory unification: double and doubtful. Philosophy of the Social Sciences, 31 (4): 488-506.

2000. Kinds of assumptions and their truth: shaking an untwisted F-twist. Kyklos, 53 (3): 303-322.

2000. Performance against dialogue, or answering and really answering: a participant observer's reflections on the McCloskey conversation. Journal of Economic Issues, 34 (1): 43-59.

1999. Science as a free market: a reflexivity test in an economics of economics. Perspectives on Science, 7 (4): 486-509.

1998. The handbook of economic methodology, eds. John B. Davis, D. Wade Hands, and Uskali Mäki. Cheltenham: Edward Elgar.

1998. Economics and methodology: crossing boundaries, eds. Roger Backhouse, Daniel Hausman, Uskali Mäki, and Andrea Salanti. Houndmills: Macmillan.

1998. Against Posner against Coase against theory. Cambridge Journal of Economics, 22 (5): 587-595

1995. Diagnosing McCloskey. Journal of Economic Literature, 33 (3): 1300-1318.

1994. Isolation, idealization and truth in economics. In Idealization in economics, eds. Bert Hamminga, and Neil De Marchi, special issue of Poznan Studies in the Philosophy of the Sciences and the Humanities, 38: 147-168.

1993. Rationality, institutions and economic methodology, eds. Uskali Mäki, Bo Gustafsson, and Christian Knudsen. London: Routledge.

1992. On the method of isolation in economics. In Idealization IV: Intelligibility in Science, ed. Craig Dilworth, special issue of Poznan Studies in the Philosophy of the Sciences and the Humanities, 26: 319-354. 
1992. The market as an isolated causal process: a metaphysical ground for realism. In Austrian economics: tensions and new developments, eds. Bruce Caldwell, and Stephan Boehm. Boston: Kluwer Academic Publishers, 35-59.

1990. Scientific realism and Austrian explanation. Review of Political Economy, 2 (3): 310-344.

1990. Mengerian economics in realist perspective. History of Political Economy, annual supplement, 22 (5): 289-310.

1988. How to combine rhetoric and realism in the methodology of economics. Economics and Philosophy, 4 (1): 89-109.

Uskali Mäki’s Website: < $\underline{\text { www.helsinki.fi/filosofia/tint/maki/index.htm> }}$ TINT Website: <www.helsinki.fi/filosofia/tint/> 